\title{
Determinants of the Quality of Life of Patients with Type 2 Diabetes in Yunnan of China
}

\author{
Qionghua $\mathrm{LV}^{1}$, Daniel Reinharz ${ }^{2}$, Qiuping $\mathrm{YANG}^{3}$ \\ ${ }^{1}$ (Department Of Endocrinology, First Affiliated Hospital OfKunming Medical University, China) \\ ${ }^{2}$ (Institute Of The Francophone For Tropical Medicine And International Health, Laos) \\ ${ }^{3}$ (Geriatric Department, First Affiliated Hospital OfKunming Medical University, China)
}

\begin{abstract}
:
Objective:The Aim of the study was to evaluate the quality of life and its determinants in patients with type 2 diabetes $(T 2 D)$.

Materials and Methods: A case-control study was performed to compare the QOL between two groups: the first group consisted of 154 patients with T2D and the second group of 154 patients without diabetes in the first affiliated hospital of Kunming Medical University and the Panlong district hospital in the Yunnan province in China.Five questionnaires were used to collect sociodemographic and clinical data, self-care activities, depression and social support data.

Results: Diabetic patients have a lower quality of life on the physical and mental dimensions compared to patients without diabetes. The gender and depression werefound to be associated significantlywith QOL on both dimensions. Several factors were significantly associated with the patients' $Q O L$ on the physical dimensions: age, social support, compliance with doctors'recommendations, diabetes duration and self-care activities. The residence was found to be associated only with the mental dimensions of the QOL.

Conclusion:Self-care activities, treatment for depression and social support might be the key interventions to considertoimprove the $Q O L$ of $T 2 D$ patients.
\end{abstract}

Keywords: quality of life $(Q O L)$, type 2 diabetes $(T 2 D)$, determinants, self-care, depression, social support.

\section{Introduction}

As a major chronic illness, diabetes has become one of the most challenging health problems worldwide [1]. In 2015, some 415 million people worldwide, or $8.8 \%$ of adults aged 20-79, are estimated to have diabetes [2]. Over 90\% of diabetes patients suffer from T2D [3]. International Diabetes Federation（IDF） estimates that the world population suffering from diabetes will increase to 642 million in 2040, due to the rapid changes in lifestyle, population ageing and urbanization [2].

In China, the prevalence of diabetes is increasing rapidly. The most recent national survey on diabetes, conducted in 2010, indicated that the estimated prevalence of diabetes in adults was $11.6 \%$ and the prevalence of prediabetes $50.1 \%$. This may represent up to 113.9 million Chinese adults with diabetes and 493.4 million with prediabetes [4].

Providing the highest as possible quality of life (QOL) to patients is supposed to be the ultimate goal of all health interventions. People with diabetes often feel challenged by T2D, the daily management demands andthe presence of complications. All these may have a negative impact on a diabetic individual's QOL [5]. Presently, in China, especially in Yunnan, it is widely admitted that doctors still haven't given enough importance to their patients' QOL. This is reflected by the fact that there are fewsystematical studies on this issue.

The objective of our study is to provide information that is still missing on the QOL of diabetic patients in order to help decision makers to better evaluate the care offered currently to people suffering from diabetes in the province of Yunnan.

\section{II.Materials And Methods}

A case-control studywas conducted betweenApril and June,2016.A total of308 participantswere randomly selected in two hospitalsin Kunming, Yunnan province: the first affiliated Hospital of Kunming Medical University and Panlong district hospital. The population was categorized in two groups:Cases consisted of T2D patients who were hospitalized in the department of endocrinology or the department of general internal medicine. Controls consisted of non-diabetic patients who were hospitalized in the department of general internal medicine, the department of ophthalmology or in the ENT department. One case and one control were matched by sex, hospital and age (in the same age group with difference of no more than 5 years).

Inclusion criteria 
1) People had to be hospitalized in one of two hospitals mentioned during the study period

2) People had to be 18 years old or older and have T2D known for at least 3 months

3) Patients had to agree to participate in the study

4) Patients had to be conscious and able to clearly express their views

5) The diagnosis of cases had to base on WHO criteria for the diagnosis of type 2diabetes [6]

\section{Exclusion criteria}

1) They were not able to answer the questionnaire

2) They had type 1 diabetes or another type of diabetes

3) They were too sick to answer the questionnaire

4) They refused to participate in the study

\section{Sources of information}

Data were collected through 5 questionnaires; four of them were administered for all participantsenrolled in the study: 1) a sociodemographic and clinical questionnaire; 2) the SF-12v2 (medical outcome short-form 12 item health survey) was used to measure the quality of life.It is a shortened form of the SF-36v2 Health Survey. However, due to brevity of the assessment, the only 2 scores obtained from this assessment are composite scores representing physical health and mental health composite summaries; 3) the ZUNG Self-rating depression scale to assess the level of depression; 4) the SSRS (Social Support Rating Scale) to evaluate social support. An additional questionnaire named Diabetes Self-Care Activities measure was applied to assess the level of self-care among patients with diabetes.

\section{Results}

\section{Socio-demographiccharacteristicsof the entire sample}

308 patients were included in this study. The majority come from one of the 2 hospitals. $54 \%$ of individuals are 60 years or older. More than half of them are male (62.34\%). Nearly all participants belonged to the Han ethnic group. Approximately $60 \%$ of people completed secondary school. Most of the people live in the city.

\section{Clinical characteristics of the case group}

There are 154 cases of diabetes, 142(92\%) patients have complications. The average duration of diabetes is 8.77 years, $58 \%$ of them have duration $\geq 10$ years. More than $80 \%$ of patients have HbAlc is higher than $7 \%$ (Table 1).

Table 1: clinical characteristics of diabetes patients

\begin{tabular}{|c|c|c|c|}
\hline Variables & $\begin{array}{c}\text { Frequency } \\
(\mathrm{N}=154)\end{array}$ & $\begin{array}{c}\text { Percentage } \\
(\%)\end{array}$ & $\begin{array}{l}\text { Mean } \\
(\mathrm{SD}=)\end{array}$ \\
\hline $\begin{array}{l}\text { Blood sugar } \\
\text { Fastimg plasma glucose } \\
\text { Posprandial blood glucose } \\
\text { BMI } \\
\text { HbAlc } \\
<7.0 \% \\
27.0 \% \\
\text { Diabetes duration } \\
<10 \text { years } \\
\geq 10 \text { years } \\
\text { Complications } \\
\text { None } \\
1.3 \\
3.5 \\
>5 \\
\text { Doctor's recommendations } \\
\text { Always often } \\
\text { Occasionally+not at all } \\
\text { Climical follow-up } \\
\text { Always+often } \\
\text { Occasionally+not at all }\end{array}$ & $\begin{array}{lr} & \\
& 126 \\
& \\
& \\
& 90 \\
& 64 \\
& \\
12 & \\
101 & \\
32 & \\
9 & \\
118 & \\
36 & \\
79 & \\
75 & \end{array}$ & $\begin{array}{l}18.18 \\
81.82 \\
\\
58.44 \\
41.56 \\
\\
7.79 \\
65.58 \\
20.78 \\
5.84 \\
\\
76.62 \\
23.38 \\
51.30 \\
48.70\end{array}$ & $\begin{array}{l}8.93( \pm 2.58) \\
12.78( \pm 4.02) \\
23.61( \pm 3.06) \\
9.22( \pm 2.80) \\
8.77( \pm 5.51)\end{array}$ \\
\hline
\end{tabular}

\section{Scores of questionnaires in entire sample}

The means scores for both summary scales of SF12v2 are less than 50 on a $0-100$ scale. The mean score of depression is 40.02. 12 patients had adepression (10 mild, 1 moderate, 1 severe).The score of social 
support range from 25 to 56, with a mean at 39.51(Table 2)

Table 2: scores of questionnaires in entire sample

\begin{tabular}{|c|c|c|c|c|}
\hline $\begin{array}{l}\text { Variables } \\
(\mathrm{N}=308)\end{array}$ & ency & $\begin{array}{l}\text { Percentage } \\
(\%)\end{array}$ & $\begin{array}{l}\text { Mean } \\
(\mathrm{SD} \pm)\end{array}$ & Min-Max \\
\hline \multicolumn{5}{|c|}{ Quality of life } \\
\hline PCS (0-1 & & & $42.80( \pm 7.52)$ & 21.6 - 58.6 \\
\hline $\operatorname{MCS}(0-1$ & & & $46.03( \pm 5.62)$ & $24.8-62.7$ \\
\hline Depressio & & & $40.02( \pm 5.74)$ & 28.75-71.25 \\
\hline$<50$ & 296 & 96.10 & & \\
\hline $50-59$ & 10 & 3.25 & & \\
\hline 60-69 & 1 & 0.23 & & \\
\hline 70-79 & $\mathbf{1}$ & 0.32 & & \\
\hline \multicolumn{5}{|c|}{ Social support } \\
\hline Objective & & & $10.15( \pm 1.56)$ & 4-16 \\
\hline Subjectiv & & & $21.76( \pm 3.57)$ & $15-32$ \\
\hline Availabil & & & $7.60( \pm 1.66)$ & 4-12 \\
\hline Total sco & & & $39.51( \pm 5.08)$ & $25-56$ \\
\hline
\end{tabular}

\section{Score of Diabetes Self-Care Activities measure}

The mean score of Diabetes Self-Care Activities is 13.92, far less than the total possible score (28).The average scores of blood sugar test and foot management dimensions is low (Table 3).

Table 3: $\quad$ score of Diabetes Self-Care Activities measure $(\mathrm{N}=154)$

\begin{tabular}{|c|c|c|}
\hline Variables & $\begin{array}{ll}\text { Mean } & \\
& (\mathrm{SD} \pm)\end{array}$ & Min-Max \\
\hline $\begin{array}{l}\text { Food management }(0-7) \\
\text { Exercise }(0-7) \\
\text { Blood sugar test }(0-7) \\
\text { Foot management }(0-7) \\
\text { Total self-care score }(0-28)\end{array}$ & $\begin{array}{l}\quad 4.90( \pm 0.90) \\
5.03( \pm 1.47) \\
1.66( \pm 0.95) \\
2.31( \pm 1.71) \\
13.92( \pm 3.16)\end{array}$ & $\begin{array}{l}2-6.4 \\
0-7 \\
0-5.5 \\
0-7 \\
5.5-21.3\end{array}$ \\
\hline
\end{tabular}

\section{Comparison of PCS and MCS scoresbetween cases and control}

T test was used to compare the score of quality of life between cases and control. People with diabetes tend to have lower PCS and MCS scores than people without diabetes. The difference is statistically significant $(\mathrm{p}<0.001)$.

Table 4:Comparison of PCS and MCS scores between cases and controls

\begin{tabular}{|l|l|l|l|l|l|}
\hline variables & \multicolumn{2}{|l|}{ Mean } & \multicolumn{2}{|l|}{$95 \% \mathrm{CI}$} & $\mathrm{P}$ \\
\cline { 2 - 6 } & $\begin{array}{l}\text { Case } \\
\mathrm{N}=154)\end{array}$ & $\begin{array}{l}\text { Control } \\
(\mathrm{N}=154)\end{array}$ & \multicolumn{2}{|l|}{} \\
\hline PCS & 40.53 & 45.07 & 41.96 & 43.64 & $<0.001$ \\
\hline MCS & 42.82 & 49.24 & 45.40 & 46.66 & $<0.001$ \\
\hline
\end{tabular}

\section{Multivariate analyses}

The multivariate conditional logistic regressions were performed using a backward stepwise approach to build the parsimonious models of the determinants of the QOL with the entire sample (Table 5, Table 6).The multivariate linear regressions were conducted using a backward stepwise approach to analyze the determinants of the outcomes in the case group (Table 7, Table 8).

Table 5:Final model of the conditional logistic regression on PCS score in the entire sample

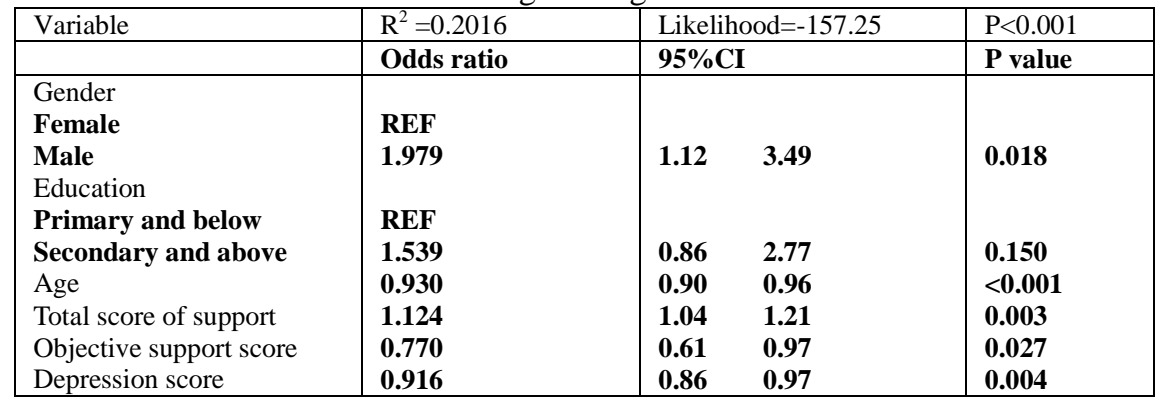

REF: Reference category

Table 6:Final model of conditional logistic regression on MCSscore $\mathrm{N}=308$ 


\begin{tabular}{|c|c|c|c|c|}
\hline \multirow[t]{2}{*}{ Variable } & $\mathrm{R}^{2}=0.19$ & \multicolumn{2}{|c|}{ Likelihood $=-131.10$} & $\mathrm{P}<0.001$ \\
\hline & Odds ratio & $95 \%$ & & P value \\
\hline Rural & REF & & & \\
\hline Urban & 0.393 & 0.18 & 0.84 & 0.016 \\
\hline Profession & & & & \\
\hline Retired+ housewife +unemployed & REF & & & \\
\hline People who work & 0.440 & 0.23 & 0.86 & 0.016 \\
\hline Total score of support & 1.072 & 0.99 & 1.16 & $\mathbf{0 . 0 8 8}$ \\
\hline Objective support score & 1.229 & 0.93 & 1.62 & 0.143 \\
\hline Depression score & 0.805 & 0.74 & 0.87 & $<0.001$ \\
\hline
\end{tabular}

REF: Reference category

Table 7:Final model of stepwise linear regression on PCS score in case group

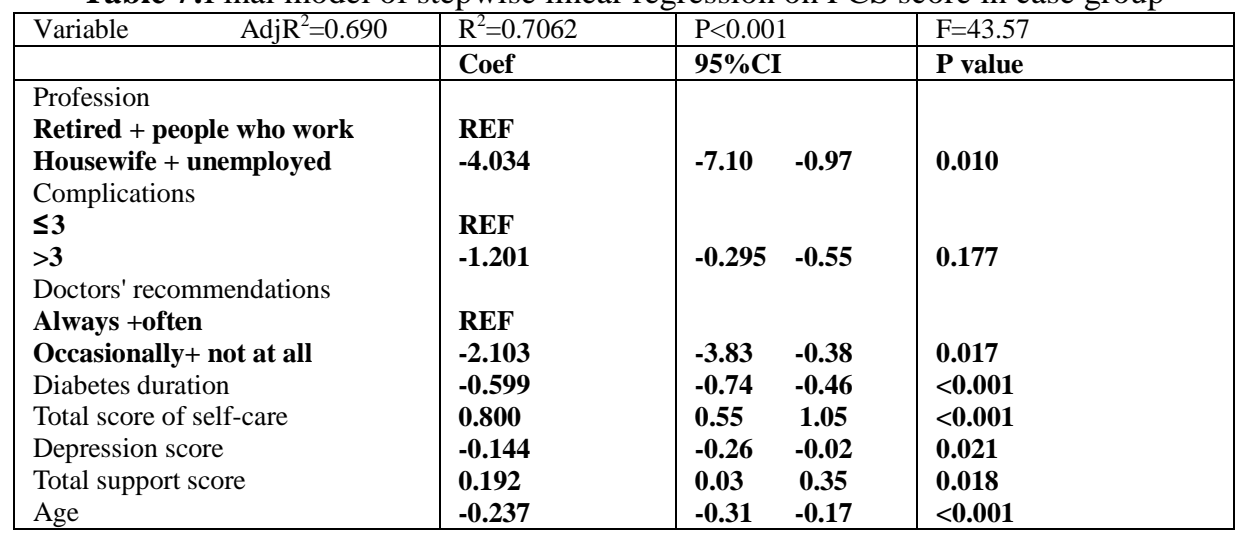

REF: Reference category

Table 8: Final model of stepwise linear regression on MCS score in case group

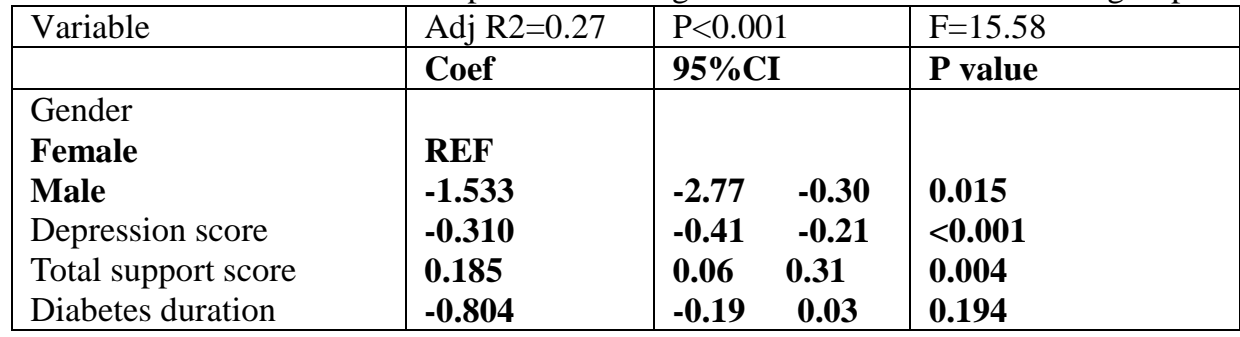

REF: Reference category

\section{Discussion}

The present study concludes that diabetic patients have a lower quality of life compared to those without diabetes, on PCS and MCS measured by SF-12v2. This result was expected as they confirm what others have reported [7, 8]. Several factors were significantly associated with the patients' QOL. Firstly, in the present study we observed that QOLon PCS was related with age. This result is not surprising and has been shown elsewhere [7,9]. Indeed, studies show that the QOL is generally higher among young people than in elders. From a public health perspective, this result underlines the importance of considering the patient globally, with all his ailments that are more frequent with age and that affect his mobility and capacity to perform in the society. Diabetes should not be managed as a disease, butas one affliction among several ones that might occur in an elder individual.In addition, the present study showed that living in a rural setting makes people more likely to have a high MCS score compared to living in an urban area.It has been reported that there is no significant differences in the quality of life between rural diabetics and urban diabetics in other study [10].The possible explanation for our result may be thatlarge families and the residential stability of rural communities can decrease isolationand providemore social support and interaction, relative to urbancounterparts. [11]

Secondly, the final regression model in people with diabetes indicates that, as expected, practicing self-care was clearly associated with a better QOL, especially on the physical health dimension. Self-care is a multi-dimensional concept. From a clinical perspective, this opens the door to several following activities that should be recommended and followed-up in order to improve patients' QOL

The first activity is related to exercise which was found to be associated with a higher QOL in people with diabetes [12-14]. Indeed, moderate-intensity (e.g. brisk walking) to vigorous-intensity exercises $\geq 150$ mins per week has been proven to confer significant benefits in the prevention of T2D onset and delay itscomplications 
$[15,16]$.

Diet is the second self-care activity. QOL is impaired in patients with diabetes, especially for the 'freedom to eat' domain, an intervention to improve dietary freedom might be a good way of improving QOL[17]. Althoughthere is not a "one-size-fits-all" pattern of eating with diabetes [18] and it's difficult for patient to adjust or change their eating patterns, health workers still should strengthen patients' perception and encourage them to eat as healthfully as possible.

Another self-care activity related to self-care is the compliance with blood sugar measurement. In our study, nobody took regular blood sugar tests. The average number of tests was only 1.66 times a week.Therefore, educating and encouraging patients to control more regularly their blood sugar is necessary. This is not such an easy objective to reach as promoting exercise, good nutrition and foot care. Certain studies showed that blood glucose testing was associated with a negative impact $[19,20]$. Authors explain that self-monitoring blood glucose more than one time per day was significantly related to higher levels of distress, worries, and depressive symptoms.

Thirdly, social support came out as another key factor of QOL among diabetic patients. More social support was associated with better QOL. This result is consistent with prior studies, which indicated that social support, as a general concept, plays an important role in the quality of life of diabetic patients [21]. In addition it is known that diabetic patients with greater support are more prone to follow their dietary regimen and toengage in physical activities. They also experience less diabetes-related distress [22]. From medical perceptive, encouraging family members of patients to create a good family atmosphere to make patients have a good emotional stateisan important element of treatment, as is promoting diabetic patients association, where people can share their problem and look together for solutions.

Fourthly, as it has been showed in previous studies [23], depression is significantly correlated with a lower QOL. Both physical and mental quality of life scores were related to depression score in the present study. As it is well known, diabetic patients have an increased risk for depressive symptoms. Yet, only a small percentage of diabetics are diagnosed with a depression [24]. From a medical perspective, this result suggests that doctors should be preoccupied by the impact of the disease on the mental health of the patient. Diabetes can affect mental health which in turn can affect the QOL of the patient. Providing information and the support able to reducedepressive symptoms should be considered as a key element of the treatment, beside the control of glycaemia. If the doctor is not aware of a patient depression or if he fails to provide treatment for this disease, depression might become an important contributor of poor self-care, poor adherence to medical treatment, higher rates of medical morbidity and mortality and increased health-care costs [25].

Finally, the present study reported that longer diabetes duration and a poor compliance with doctors recommendations were related to a lower score in the physical dimension of the quality of life. It is noteworthy that the final model of the present study showed no connection between QOL and diabetic complications, on the contrary to what was expected $[17,26]$. The possible explanation would be that in our study, almost no serious complications occurred in participants, although more than $90 \%$ of people had diabetes complications.

\section{Biases And Limitations}

The interpretation of the results of this study must take into consideration some facts. The first limitation is that the sample wasnon-representative of the whole population of people with T2D, since the study was conducted only in 2 hospitals in Kunming, the capital Yunnan province. Participants were patients who were sent to the 2 hospital (hospitalization). It can therefore be assumed that the expansion of research on outpatients or patients living in other areas could demonstrate differences in the assessedvariables. In the future, it would be advisable to assess a sample representative for the population: a large group ofpeople with a random selection of individuals. The secondlimitation is that as the data collectionrelied on the questionnaire, we cannot exclude the possibility thatsome of the respondents might have had difficulties in understanding some questions, or that some people provided answers aimed atpresenting themselves in the best possible manner.Another limitation is thatonly one measure of QOL was usedin the present for comparability (SF-12v2). It is important to keepin mind that SF-12 is a generic measure, not a DM-specific QOL instrument.Moreover, it allowed to compare only 2 dimensions, the physical and mental ones, while other dimensions of the QOL concept as social interaction, might be important. A specific instrument would have allowed to catch this element.

\section{Vi. Conclusionand Recommendations}

In conclusion, the present study shows that diabetic patients have a lower quality of life on physical and mental dimensions compared to patients without diabetes. The gender and depression werefound to be associated significantlywith QOL on both dimensions. Several factors were significantly associated with the patients' QOL on the physical dimension: age, social support, compliance with doctors'recommendations, diabetes duration and self-care activities. The residence was found to be associated only with mental dimension of the QOL. 
Self-care activities, depression treatments and social support might be the keys interventions to considerimprovingthe QOL of T2D patients. The results of this study allow us to propose the following recommendations:

1.The health worker should consider diabetic patients' quality of life, beside the control of glycaemia.

2.Guiding patients to practice more regularly self-care activities is necessary.

3.Encouraging family members of patients to create a good family atmosphere to make patients have a good emotional stateisan important element of treatment. Wealso suggest promoting diabetic patients association, where people can share their problems and look together for solutions.

4.Doctors should be preoccupied by the impact of T2D on the mental health of the patients. Depressive symptoms should be considered as a key element of thetreatment.

\section{References}

[1]. International Diabetes Federation: IDF Diabetes Atlas.6th edition. Brussels, Belgium: International

[2]. Diabetes Federation, 2013

[3]. International Diabetes Federation. IDF Diabetes, 7ed. Brussels, Belgium: International Diabetes Federation, 2015.

[4]. http://www.diabetesatlas.org.

[5]. Global status report on noncommunicable diseases 2014.Geneva, World Health Organization, 2012.

[6]. $\mathrm{Xu} \mathrm{Y,} \mathrm{Wang} \mathrm{L,} \mathrm{He} \mathrm{J,} \mathrm{et} \mathrm{al.} \mathrm{Prevalence} \mathrm{and} \mathrm{Control} \mathrm{of} \mathrm{Diabetes} \mathrm{in} \mathrm{Chinese} \mathrm{Adults.} \mathrm{JAMA.} \mathrm{2013;} \mathrm{310(9):948-959.}$ doi:10.1001/jama.2013.168118.

[7]. Richard R. Rubin, Mark Peyrot. Quality of Life and Diabetes. Diabetes/Metabolism Research and Reviews 15, no. 3 (1999): 205-18.

[8]. Definition, diagnosis and classification of diabetes mellitus and its complications. Part 1: Diagnosis and classification of diabetes mellitus. World Health Organization, Geneva, 1999. Report Number: WHO/NCD/NCS/99.2.

[9]. Papazafiropoulou AK, Bakomitrou F, Trikallinou A, et al. Diabetes-dependent quality of life (ADDQOL) and affecting factors in patients with diabetes mellitus type in Greece. BMC Research Notes.2015; 8:786, doi: 10.1186/s13104-015-1782-8.

[10]. Chung JO, Cho DH, Chung DJ, Chung MY. Assessment of factors associated with the quality of life in Korean type 2 diabetic patients. Intern Med.2013; 52:179-85.

[11]. Bradley C, Speight J. Patient perceptions of diabetes and diabetes therapy: assessing quality of life. Diabetes Metab Res Rev. 2002; 18:64-9.

[12]. Dudzinska, Marta, Jerzy S. Tarach. 'Type 2 Diabetes Mellitus in Relation to Place of Residence: Evaluation of Selected Aspects of Socio-Demographic Status, Course of Diabetes and Quality of Life-a Cross-Sectional Study'. Annals of Agricultural and Environmental Medicine 20, no. 4 (2013).

[13]. Quandt, Sara A., Christopher N. Graham, et.al. ETHNIC DISPARITIES IN HEALTH-RELATED QUALITY OF LIFE AMONG OLDER RURAL ADULTS WITH DIABETES.Ethn Dis 17, no. 3 (2007): 471-76.

[14]. Smith DW, McFall SL. The relationship of diet and exercise for weight control and the quality of life gap associated with diabetes. J Psychosom Res. 2005; 59:385-92.

[15]. Myers, V. H., M. A. McVay, M. M. Brashear, et.al. Exercise Training and Quality of Life in Individuals With Type 2 Diabetes: A Randomized Controlled Trial. Diabetes Care 36, no. 7 (1 July 2013): 1884-90.

[16]. Nicolucci A, Balducci S, Cardelli P, et al; Italian Diabetes Exercise Study Investigators. Relationship of exercise volumeto improvements of quality of life withsupervised exercise training in patients with type 2 diabetes in a randomized controlled trial: the Italian Diabetes and Exercise Study (IDES). Diabetologia 2012; 55:579-588.

[17]. Knowler WC, Barrett-Connor E, Fowler SE, et al. Diabetes Prevention Program Research Group. Reduction in the incidence of type 2 diabetes with lifestyle intervention or metformin. The New England Journal of Medicine 346, no. 6 (7 February 2002): 393-403,doi:10.1056/NEJMoa012512.

[18]. Pan X-R, Li G-W, Hu Y-H, et al. Effects of diet and exercise in preventing NIDDM in people with impaired glucose tolerance: the Da Qing IGT and diabetes study. Diabetes Care. 20:537, 1997.

[19]. Wang HF, Yeh MC. The quality of life of adults with type 2 diabetes in a hospital care clinic in Taiwan. Qual Life Res. 2013; 22:577-84.

[20]. Alison B. Evert, Jackie L. Boucher, et al. Nutrition Therapy Recommendations for the Management of Adults with Diabetes. Diabetes Care 36, no. 11 (11 January 2013): 3821-42, doi: 10.2337/dc13-2042.

[21]. Franciosi M, Pellegrini F, De Berardis G, Belfiglio M, Cavaliere D, Di Nardo B, et al. The impact of blood glucose self-monitoring on metabolic control and quality of life in type 2 diabetic patients. Diabetes Care.2001; 24:1870-7.

[22]. Yee Cheng Kueh, Tony Morris et al. Modelling of diabetes knowledge, attitudes, self-management, and quality of life: a cross-sectional study with an Australian sample. Health Qual Life Outcomes.2015; 13: 129.

[23]. Tang, Tricia S., Morton B. Brown, Martha M. Funnell, and Robert M. Anderson. Social Support, Quality of Life, and Self-Care Behaviors Among African Americans With Type 2 Diabetes. The Diabetes Educator 34, no. 2 (3 January 2008): 266-76, doi: 10.1177/0145721708315680.

[24]. Whittemore R, D’EramoMelkus G, Grey M. Metabolic control, self-management and psychosocial adjustment in women with type 2 diabetes. J ClinNurs.2005; 14:195-203.

[25]. Miranda T Schram, Caroline A Baan, and François Pouwer. Depression and Quality of Life in Patients with Diabetes: A Systematic Review from the European Depression in Diabetes (EDID) Research Consortium. Curr Diabetes Rev. 2009 May; 5(2): $112-119$.

[26]. Pouwer F, Beekman AT, Lubach C, Snoek FJ. Nurses' recognition and registration of depression, anxiety and diabetes-specific emotional problems in outpatients with diabetes mellitus. Patient EducCouns. 2006; 60: 235-40.

[27]. Ciechanowski PS, Katon WJ, Russo JE. Depression and diabetes: impact of depressive symptoms on adherence, function, and costs. Arch Intern Med 2000; 160: 3278-85.

[28]. Holmanova E, Ziakova K. Audit diabetes dependent quality of life questionnaire: usefulness in diabetes self-management education in the Slovak population. J ClinNurs.2009; 18:1276-86. 